\title{
La suave Patria: un poema posrevolucionario.
}

\section{La suave Patria: a post-revolutionary poem.}

DOI: $10.32870 /$ sincronia.axxv.n80.13b21

\author{
Andrea Murillo \\ Universidad de Guadalajara (MÉXICO) \\ CE: andy 192122@hotmail.com / ORCID: 0000-0003-1773-1312
}

Esta obra está bajo una Licencia Creative Commons Atribución-NoComercial 4.0 Internacional

Recibido: 30/09/2020

Revisado: 06/05/2021

Aprobado: 17/06/2021

\section{RESUMEN}

El presente trabajo tiene como objetivo señalar que La suave Patria (1921) de Ramón López Velarde es un poema en el que no solo se encuentra un cántico afable a la patria, lectura predominante desde su publicación, sino que en él conviven versos de crítica social con aquellos que enaltecen el amor nacionalista necesario en un momento de reestructuración nacional, tal como lo fue el periodo posrevolucionario en México. De esta forma, es cierto señalar que existe una loa patriótica en el texto, gracias a la recurrencia de rasgos de asociación amorosa con respecto al lugar de origen, pero, también, es correcto considerar la evidencia en los versos de una representación del contexto en conflicto al que pertenece, siendo la ironía la herramienta principal que vele dicha crítica y las constantes contradicciones que dan forma a esta pieza lopezvelardeana.

Palabras claves: Ramón López Velarde, poesía mexicana, nacionalismo, crítica social, Revolución mexicana.

\section{ABSTRACT}

The present work aims to point out that La suave Patria (1921) by Ramón López Velarde is a poem in which not only is there an affable song to the homeland, a predominant reading since its publication, but verses of social criticism with those who extol the necessary 
nationalist love at a time of national restructuring, such as was the post-revolutionary period in Mexico. In this way, it is true to point out that there is a patriotic loa in the text, thanks to the recurrence of traits of loving association with respect to the place of origin, but, also, it is correct to consider the evidence in the verses of a representation of the context in conflict to which it belongs, being irony the main tool that veils this criticism and the constant contradictions that give shape to this piece from Lopez-Velarde.

Keywords: Ramón López Velarde, Mexican poetry, nationalism, social criticism, Mexican Revolution.

La suave Patria (1921) de Ramón López Velarde (1986), ha sido una obra receptora de innumerables comentarios y análisis críticos desde su aparición. Aun así, resulta inevitable revisitar el texto a cien años de su publicación con el objetivo de resaltar que en el poema existe crítica social concerniente al contexto posrevolucionario en el que está inscrito. El texto lopezvelardeano fue considerado, durante todo el siglo $\mathrm{XX}$, como uno intimista que se limitaba evocar un pasado destruido por la Revolución, ese antaño provinciano que contiene lo típicamente mexicano y es abrazado y defendido amorosamente por el autor. El afecto vertido en los versos ha provocado que sean éstos los protagonistas del texto, restando relevancia a aquellas estrofas que le permiten al poema ser reconocido como uno, cuyo contenido, involucre crítica social.

La vuelta al pasado en La suave Patria aparece como una utopía que, siguiendo a Carlos Monsiváis, opera únicamente a nivel literario; señala, además, que no existe idealización en el texto debido a que el contenido se ofrece sólo "como un caudal poético". La poesía promete esta posibilidad, pero, contrario a lo defendido por el crítico, también es capaz de trascender más allá de la percepción estética que permite ver en este texto no sólo la armónica convocación de la provincia, sino la posibilidad de colocarlo en el sitio de las obras que dejan ver en ellas representados los conflictos sociales propios de un tiempo en transición.

El presente análisis no pretender revelar "¿Qué quiso decir el autor?", sino descubrir una de las perspectivas que ofrece el texto y averiguar qué implica la convocación de la provincia en un poema surgido para satisfacer un proyecto nacionalista posrevolucionario; asimismo, se busca 
reconocer cómo operan las contradicciones semánticas expuestas en el texto, principalmente, aquellas que funcionan bajo el velo de la ironía, recurso que resulta imposible pasar por alto, gracias a que reviste aquellos momentos reveladores de lo que puede considerarse la puesta en escena de la situación social de un momento de esencial importancia en la historia del país y en la reformulación de identidad nacional.

\section{"El Ayer diáfano y el Hoy angustioso"}

El teórico Gerard Genette, en su libro Umbrales (2001), propone que un paratexto puede responder a diferentes categorías, entre ellas los títulos temáticos que son con los que se identifica el expuesto aquí; es decir, aquellos que apelan al contenido del texto. Se puede estar ante títulos temáticos literales, de asociación por sinécdoque o metonimia, simbólicos o antitéticos según sea su relación con el desarrollo del cuerpo de la obra (p. 73). El vínculo de sinécdoque o metonimia y aquel de valor simbólico quedan anulados como alternativa considerando que, en el primer caso, no hay una asociación entre el título y algún objeto menos central que se encuentre dentro del poema; por otro lado, la segunda opción, el simbólico, se descarta, debido a que el paratexto no funciona como metáfora con respecto al contenido.

La designación clara del tema por parte del título podría pensarse como un hecho que vuelve literal al paratexto, esto, gracias a la aparente obviedad de que el objeto central del poema es la patria, lo cual resulta innegable, no obstante, el adjetivo suave lleva a considerar la posibilidad de que La suave Patria corresponda a un título antitético, gracias a los señalamientos que se han hecho con respecto a la presencia de la ironía en los versos.

La ironía es una figura de pensamiento que permite "presuponer del sujeto lo contrario de lo que exige el contexto" (Foxley, 2016, p.7); es decir, se trata de un enunciado que provoca una oposición semántica, gracias a las demandas contextuales planteadas al momento de la enunciación. Así como lo dicho sintagmáticamente es relevante para reconocer la ironía, también el nivel extratextual funge como fuente reveladora de sentido. El contexto lingüístico del título que ocupa aquí no permite conjeturar que se está ante dos categorías contradictorias, no es sino hasta 
observar que tanto indicadores contextuales en el desarrollo del poema, así como indicios extratextuales, abonan al reconocimiento de que resulte irónico calificar como suave a la patria.

La figura de discurso irónica, siguiendo a Søren Kierkegaard (2000), se caracteriza por "cierta superioridad", debido a que aparece como un recurso que busca ser entendido, pero no de manera literal. Es una figura que desdeña el discurso llano que en el acto es entendido por todos, la que, además:

[...] se da en los círculos más altos como una prerrogativa perteneciente a la misma categoría que el bon ton [buen tono], que exige que se sonría ante la inconciencia y que la virtud sea vista como estrechez, pese a que, en alguna medida, se cree en ella. (p. 288).

La ironía puede presentarse mostrando una relación de oposición entre el que enuncia y lo enunciado; así, el ironista es capaz de aparentar ante el mundo exterior una actitud que no le es propia. Él "goza de la total infinitud del amor, y la expansión que otros buscan en sus confidentes, él la consigue en el hecho de haber revelado a viva voz que nada sabe" (p. 290). La voz lírica de La suave Patria se enuncia con un "Yo" inicial y recurre a la minimización de sus dotes para comenzar sus disertaciones sobre la patria:

Yo que sólo canté de la exquisita

partitura del íntimo decoro,

alzo hoy la voz a la mitad del foro

a la manera del tenor que imita

5 la gutural modulación del bajo,

para cortarle a la epopeya un gajo.

Navegaré por las olas civiles

con remos que no pesan, porque van

como los brazos del correo chuan 
que remaba la Mancha con fusiles. ${ }^{1}$

Al proemio corresponden estos versos, cuyo funcionamiento está dado por el carácter introductorio en el que se sitúan. La poesía antigua se valía del preludio como ejercicio de ensayo para que el que tocaba la lira comenzara a cautivar al jurado. El relato, sin aparente origen, se inaugura con palabras arbitrarias que dan inicio al posterior canto (Barthes, 1966, p. 32). En este proema, el sujeto lírico recurre al tópico de la falsa modestia, cuya funcionalidad se encuentra en la misma que los textos clásicos, donde las fórmulas de "humildad", "debilidad" o "escasa preparación" permiten el empequeñecimiento del que habla para ganar la benevolencia del que escucha o lee.

El sintagma correspondiente al tópico de la falsa modestia se lee en su origen como un recurso cuya existencia respondía a una excusa necesaria determinada por la tradición literaria; no obstante, se puede hablar de una evolución del tópico que transforma la exigencia poética en una estrategia que el contexto no requiere, por lo que se torna irónica. De esta forma, dicha expresión se convierte en una sujeta a un proceso de relexicalización. A decir de Edmond Cros acerca de la reelaboración de lexías:

[...] la manera de deslexicalizarse a veces estas expresiones para relexicalizarse con formas nuevas dentro de un texto, bajo el efecto evidente de las estructuras profundas de este texto, hace más aparente los criterios de elección seguidos por el mensaje en los ejes paradigmáticos en el momento en que se instituye. $(1986,29)$.

La estrategia de falsa modestia utilizada por la voz lírica se lee ya no como una forma protocolaria imprescindible del contexto, sino como un recurso útil para recordar que a la patria se le habla en un tono ligero y sin reproche. De esta forma, en un momento donde es necesario hacer resurgir el amor patrio, tratar sutilmente a la patria es un procedimiento que se adapta a las necesidades didácticas del nacionalismo posrevolucionario.

\footnotetext{
${ }^{1}$ Todas las citas que aparecen en este análisis del poema "La suave Patria" de Ramón López Velarde son tomadas de la edición Ramón López Velarde. Obras (1986).
} 
La exegesis a la segunda estrofa de La suave Patria está hecha ya y se nutre de las interpretaciones hechas por críticos del poema como Octavio Paz, José Emilio Pacheco o Alfonso García Morales. Éste último recuerda la influencia que hay, en este apartado del proemio, de la novela francesa Le chevalier Destouches (1864), inspirada en el tema de la rebelión de los chuanes contra el gobierno de la Revolución francesa, situación que podría evidenciar la posición conservadora con la que se presenta la voz lírica (García, 2011, párr.18).

La postura de Paz ante estos versos es similar cuando afirma:

La suave Patria no es un canto a las glorias o desastres nacionales. Al iniciar el poema [...] advierte: «navegaré por las olas civiles con remos que no pesan...» Y lo cumple: no hay apenas alusiones a la historia política y social de México, ni a sus héroes, caudillos, tiranos y redentores. (1963, p. 14).

La defensa que se hace del poema como un texto intimista, que no reacciona ante las circunstancias sociales, resulta pertinente cuando se considera que no se está ante una obra cuyo discurso se asocie a la poesía social, la cual encuentra su esencia en la denuncia que hace, a viva voz, de abusos e injusticias cometidas por aquellos que manipulan el poder. No obstante, La suave Patria es un texto literario que, como tal, se desvía de los enunciados que en la realidad son comprobables, para convertirse en una práctica discursiva que evidencia una serie de contradicciones ideológicas entre lo que debería ser y lo que objetivamente existe. Siguiendo a Edmond Cros:

El texto literario, como la práctica discursiva en que se basa, pondría en escena la ficción de la solución imaginaria de contradicciones ideológicas inconciliables. La función de la literatura consistiría así en ocultar la dominación de clase bajo las apariencias de la universalidad y de la unidad. (1986, p. 43)

evitar mostrar ese "gajo" de historia que se forma en el contexto posrevolucionario, confuso por su naturaleza. La situación contextual del poema permite ver que irónica resulta la estrofa pareada que sigue de la advertencia de ir ligero entre las olas:

Diré con una épica sordina 
la Patria es impecable y diamantina.

El oxímoron que se suma a los constantes opuestos planteados en el texto aparece con miras de hacer discreta la sentencia que atribuye, como de manera inapelable, los rasgos de "impecable" y “diamantina” a la patria. Hervé Le Corre (2010) afirma que “'cortar [...] un gajo' a la 'épica sordina', impide sin duda que "La suave patria' [sic] sea un 'gran' poema - porque es, en cierta medida, un poema programático y transigente" (p. 3). La postura programática reconocida en el poema responde a la evasión evidente en líneas que, más que hablar de la situación actual de enunciación, recurren a la utopía y a la defensa del presente a partir las glorias del pasado. Asimismo, la transigencia se piensa después de la aparente nula exposición de aquellos factores políticos, sociales y económicos que pongan en entre dicho la validez de los adjetivos asignados a la nación.

La provincia mítica evocada en el texto aparece con mayor frecuencia que las estrofas pareadas o los tercetos, donde se hace patente la ironía, a partir de lo cual se infiere el éxito que concede al poema, como principal aportación, el ejercicio de exaltación del nacionalismo mexicano, motivo del surgimiento del texto, y no bien la celebración de éste por los asomos antitéticos que vuelven al poema un juego de constantes oposiciones.

La voz lírica plantea su relación con la patria a partir de la evocación de un tiempo pasado que se convierte en el espacio edénico que sirve como ejemplo paradigmático de lo que en adelante responderá a aquellas motivaciones que sustenten la necesidad de declarar amor a la nación. Si los valores actuales en los que se inserta el poema no son suficientes para legitimar el apego a la patria, un recurso adecuado será recordar las escenas que glorifican el pasado. Así, al no poder pintar sin equívocos el paraíso vivido, el sujeto lírico recurre a exponer una representación idealizada del lejano mundo en el nuevo territorio, uno caracterizado por ser confuso y poco prometedor.

Suave Patria: permite que te envuelva en la más honda música de selva 
al golpe cadencioso de las hachas, entre risas y gritos de muchachas y pájaros de oficio carpintero.

\section{Primero fue Paraíso, después, Tierra}

La cadencia a la que alude el movimiento de las hachas, la alegría de las jóvenes y el sonido de las aves convocadas en el proemio son características que responden a imágenes que configuran una tierra prometida ya inexistente, como se observa en el transcurrir del poema. Este planteamiento lleva a asociar al texto con el tópico surgido del poema El paraíso perdido del inglés John Milton (1667). El texto, de ascendencia épica, principalmente virgiliana, tiene como tema principal la caída del hombre y sus consecuencias; así como las formas enigmáticas en las que Dios interviene en la vida terrenal, esto a través de la recuperación del mito de Adán y Eva. Al aceptar su exilio, después de comer del árbol prohibido, ella se lamenta:

¡Oh golpe inesperado, peor que la muerte! ¡Conque he de abandonarte, oh Paraíso! ¡Abandonaros de esta suerte, a ti! ¡Oh suelo natal, y a vosotras alamedas encantadoras, florestas dignas de ser frecuentadas por los dioses! (2003, p.152).

Los sentimientos de aflicción, arrepentimiento y remordimiento se insertaban en la conciencia del hombre a partir de sucumbir ante la seducción del árbol de la vida. La noción del bien perdido y del mal ganado ocuparía un lugar privilegiado en su percepción existencial. El discurso de La suave Patria recurre a la remembranza de los buenos tiempos y cuestiona en el Primero acto:

¿Quién, en la noche que asusta a la rana, no miró, antes de saber del vicio,

40 del brazo de su novia, la galana pólvora de los fuegos de artificio? 
La mirada al pasado placentero muestra la carencia en el presente de aquello que podría identificarse como la Edad de Oro, en la que, siguiendo a Hesiodo (700 a.C.) en su obra "Los trabajos y los días", los hombres podían vivir como dioses y poseían un espíritu tranquilo. No sabían del dolor, el trabajo ni la insufrible vejez; asimismo, podían disfrutar de todos los bienes y la abundancia de la tierra fértil que se compartía entre hombres virtuosos (Hesiodo, 2016, p. 9).

Las sátiras clásicas retomaron la utopía y actualizaron el mito de la Edad de Oro con el fin de cuestionar las condiciones sociales por las que atravesaba su contexto. El escritor griego Luciano (217 a.C.), por ejemplo, trata el tema de las fiestas saturnales en uno de sus diálogos. Dichas festividades eran celebradas cada diciembre en honor a Saturno; eran siete días en los que los opuestos se mezclaban: los ricos invitaban a los pobres a su mesa, los esclavos andaban entre los libres y las autoridades eran juzgadas por el pueblo.

La tradición se deterioró y las desigualdades no pudieron ser subsanadas ni siquiera esos días. La perversión de la fiesta dio origen a un texto, Las Saturnales, que hizo sátira acerca de las desigualdades económicas a partir de la reconsideración de una época dorada en la que Saturno gobernaba:

[...] cuando yo reinaba y cuando, sin sembrar ni arar, se les venían los frutos de la tierra, indicio grande de la fertilidad de entonces. No había paja, sino que el pan se nacía cocido, las carnes guisadas, el vino corría como agua de río, fuentes de miel y de leche topábanse a cada paso, porque los hombres todos eran buenos y hechos de oro (Luciano citado por Grigoriadu, 2010, p. 1074).

La preocupación de los habitantes ante la llegada de la celebración se hacía latente, debido a las desigualdades económicas que imperaban:

Pues fuera más razón que primero se hicieran comunes los bienes que ahora están entre pocos y, hecho esto, luego se mandara publicar la fiesta para que, con más decencia, se celebrara. Pero el mundo está de manera que o somos hormigas o camellos o, si más queréis, nos parecemos al representante trágico que sale al público con un alto coturno en un pie que es el calzado destos tragediantes-, y el otro sin coturno (ibíd. p.1082). 
La reconsideración de las bondades del pasado como estrategia para denunciar las debilidades del presente es un recurso empleado en La suave Patria. Durante el intermedio, la voz poética alude al mundo prehispánico valiéndose de la figura mítica de Cuauhtémoc:

75 Joven abuelo: escúchame loarte, único héroe a la altura del arte.

Anacrónicamente, absurdamente, a tu nopal inclinase el rosal;

al idioma del blanco, tú lo inmantas

80 y es surtidor de católica fuente que de responsos llena el victorial zócalo de ceniza de tus plantas.

No como a César el rubor patricio te cubre el rostro en medio del suplicio:

85 tu cabeza desnuda se nos queda, hemisféricamente de moneda.

Moneda espiritual en que se fragua todo lo que sufriste: la piragua prisionera, el azoro de tus crías,

90 el sollozar de tus mitologías, la Malinche, los indios a nado, y por encima, haberte desatado del pecho curvo de la emperatriz como del pecho de una codorniz. 
La conmemoración del último emperador azteca inició antes de concluir el siglo XIX. Fin de siglo que representó la llegada del progreso para los países del mundo occidental y la consecuente necesidad de afianzar una identidad propia basada en las raíces que legitimaban su esencia en peligro, gracias a la rápida instalación de la modernidad. La mirada al pasado se volvió un ejercicio ineludible para entender el presente, a partir de lo que resurgieron personajes y acontecimientos dotados de facultades virtuosas. A propósito, Lara Campos (2017) menciona: "desde el pasado más remoto al más inmediato, cualquier episodio era susceptible de ser rescatado del olvido o del conocimiento erudito si con él se podía hacer pedagogía nacional” (p.2).

La efectividad de la formación cívica en desarrollo radicó en su instalación en espacios públicos, donde se hacía accesible al pueblo en general y ya no se limitaba a las élites o sitios reducidos. El monumento a Cuauhtémoc se presentó como uno de esos "altares de la patria" que rescataba el pasado indígena, con el fin de restituirle su importancia por encima de la herencia hispánica (p. 3).

La fórmula de enaltecimiento del héroe consistió en desacreditar al enemigo español. En La suave Patria, la grandeza del pasado se instala en el presente para oponer la imagen de Cuauhtémoc a todas aquellas figuras que intentaron sostener el mote de héroe, pero que no estuvieron a la "altura", es decir, que no ostentaron los mismos valores que llevaron al emperador azteca a ser considerado como el verdadero héroe.

Las cinco estrofas del intermedio son una lección de historia que permiten celebrar al derrotado en vida que triunfa en la posteridad, rasgo que puede ser considerado como conformismo, pero que funciona como el aplauso a los méritos de un héroe vencido (De Aguinaga, 2016, p. 15). Las reflexiones traídas del plano político dan cabida a observaciones como aquellas que ven lo absurdo que resulta, a pesar del triunfo del extranjero, que surja la imagen de ese "joven abuelo" expuesto no únicamente como "un resistente paradigmático: también es, en última instancia, un seductor irresistible a cuyos pies acaba rindiéndose la cultura enemiga, ese "idioma del blanco" que, imantado por la juventud, la dignidad y la belleza del héroe, le profesa una ferviente devoción" (p. 15). La relación simbiótica es completa cuando, además de seducir al otro, la fe 
católica se impregna en las creencias del mexicano y le sirve a éste para dedicar aquellos responsos inspirados en el tormento impreso en los pies del monumento a Cuauhtémoc.

La iconografía representa la figura del héroe azteca de manera monumental, sin embargo, en La suave Patria la voz lírica destaca que su honorable existencia queda grabada en una "moneda espiritual" que encierra la historia del personaje. Alfonso García Morales (2011) señala que se trata de una reducción propia a una tendencia miniaturista y anti-monumental del poema (Morales, párr. 29). Si bien es cierto que el empequeñecimiento es un recurso empleado en otros versos, en el dedicado a esta figura histórica resultaría poco satisfactorio considerando que se trata de un pasaje, el único, en el que la exaltación se percibe grave en la enunciación.

El Paraíso transformado en Tierra se presentará como un edén subvertido, en el que ya no existen héroes y donde la modernidad pervierte el orden natural de las cosas. Siguiendo a Roger Bartra, a partir de la subversión, la sociedad industrial capitalista crea o inventa su propio paraíso perdido para buscar en un pasado mítico aquella inocencia primitiva y orden original extraviado. Es así como en el intermedio de La suave Patria se recurre a la remembranza de una figura mítica ejemplar para poner en evidencia, como señala Ainsa con respecto a traer de vuelta el pasado, un presente desprovisto de héroes a la altura del arte.

\section{Una estampa nacionalista}

El primer acto de La suave Patria es una descripción geográfica de un territorio mexicano caracterizado por sus contradicciones. El paisaje trazado en las doce estrofas de este apartado representa un escenario conformado por un ambiente donde tiene cabida una vista citadina y provinciana, y en el que se descubren cualidades de la Patria. La idea de paisaje exige el reconocimiento de éste como un ejercicio de construcción subjetiva, es decir, lo representado, ya sea pictórica, literaria u oralmente, no está ahí, sino que es el producto de una serie de ideas, sentimientos y sensaciones provocadas por la relación del que enuncia y el lugar y los elementos que lo conforman (Maderuelo, 2005, p. 14) Según Javier Mederuelo: “El paisaje es el resultado de la 
contemplación que se ejerce sin ningún fin lucrativo o especulativo, sino por el mero placer de contemplar" (p. 14).

La problematización hecha desde las diferentes perspectivas que estudian el paisaje, ha llegado a conclusiones que permiten considerarlo no sólo como una representación simbólica, sino como una manifestación ideológica e histórica. Al deleite contemplativo, finalidad reduccionista que se le dio al paisaje, se suma una función de representación del espacio sustentada en "los valores sociales hegemónicos de cada época" (Di Giminiani y Fonck, 2015, p. 5). De esta forma, quien expresa su visión del paisaje está representando para sí mismo su perspectiva del mundo, pero, al mismo tiempo, configura la que los otros tengan del mismo, modelando, así, sus relaciones sociales (p. 5). Desde este punto de vista, el paisaje se entenderá como: "el reflejo de ideales políticos dominantes [que] permite desmentir la idea de que las representaciones del entorno físico sean actos neutrales desvinculados de otros intereses" (p. 5).

La promoción del nacionalismo en México ha estado estrechamente vinculada con la actividad paisajista por esa "conciencia de territorialidad" que contribuye a fomentar el sentimiento de identidad nacional. La razón se debe a que es necesario crear lazos entre los pueblos y el paisaje, pues en este se encontrará la historia, las aspiraciones, los logros colectivos y la piscología de los habitantes. La mirada se vuelve hacia el paisaje cuando es necesario legitimar una nacionalidad en vías de construcción o reconstrucción (Ortega, 2009, p. 4)

La voz lírica de La suave Patria, con una mirada omnímoda, adjetiva cielo y tierra, a partir de lo que se crea una estampa de campo abierto que contiene lo concreto y lo abstracto que conforma a la nación:

Patria: tu superficie es el maíz,

20 tus minas el palacio del Rey de Oros,

y tu cielo, las garzas en desliz

y el relámpago verde de los loros. 
La Mesoamérica agrícola se sustenta en la realidad y el mito presente desde la época prehispánica en la que se explica que los dioses crearon al hombre a partir del maíz. El grano, dado a conocer al hombre por los dioses como un regalo, es el principio identitario en la cosmovisión del México antiguo. Desde su descubrimiento, el maíz ha sido el principal sostén alimenticio de los mexicanos, no en vano, entonces, se afirma que esta planta colme el suelo de la patria, un recordatorio de la importancia de la principal actividad económica.

La minería, al igual que la agricultura, está presente como importante componente del panorama nacional. Las características geológicas y tectónicas del territorio mexicano permitieron la existencia de diversos yacimientos minerales, lo que convirtió a esta actividad en una de las más practicada desde tiempos prehispánicos (Sánchez, Coll-Hurtado y Ramírez, 2003, p. 97). En La suave Patria la cualidad de riqueza que promete autosuficiencia otorgada por la agricultura y la minería está planteada a partir de la aparición del Rey de Oros.

La reconstrucción en el ideario colectivo de la vida agraria es un recurso que busca inventar un edén mítico con el objetivo de combatir el sentimiento de culpa surgido después de su destrucción, así como para configurar un carácter nacional homogeneizante (Bartra, p. 34). Para Roger Bartra, esta estrategia resulta indispensable "para poner orden en una sociedad convulsionada por la veloz llegada de la modernidad y sacudida por las contradicciones de la nueva vida industrial" (p. 34).

La provincia de La suave Patria es ese edén subvertido a partir del cual se intenta legitimar una identidad nacional que se niega a entrar por completo a la vida industrial posterior a la Revolución Mexicana, debido a que es necesario establecer las características de lo genuino del ser nacional antes de permitir que otro modelo utópico revolucione lo existente o lo contamine. Se hablará, así, de una arqueotopia, definida por Bartra como:

[...] la imaginación, hoy, de un lugar previo y antiguo en el que reine la felicidad; pero es una felicidad pretérita y marchita que reposa en un profundo estrato mítico, enterrado por la avalancha de la Revolución mexicana y por el que sólo podemos sentir una emoción melancólica (Bartra, p. 34). 
El pareado sucesivo a la presentación de las riquezas nacionales aparece como un hecho negativo, debido a que entra en oposición la divinidad y su dádiva y la maldad y su concesión:

El Niño Dios te escrituró un establo

24 y los veneros de petróleo el diablo.

Las prácticas económicas primitivas, la agricultura y la minería, poseen un valor positivo ante la industrialización que representan los veneros de petróleo que, aunque riqueza propia de la escena natural, durante la primera década de su explotación, fue el móvil del enfrentamiento entre el general Manuel Peláez, uno de los primeros negociadores del petróleo mexicano con compañías extranjeras, y el gobierno de Carranza, quien pretendía considerar el hidrocarburo únicamente como bien nacional. Fue así como desde su descubrimiento, el petróleo en México ha forjado una historia de disputa que involucra intereses nacionales y extranjeros, a partir de que los hidrocarburos fueran considerados de importancia significativa para para el desarrollo industrial. El subsuelo mexicano, se vislumbraba ya, durante los primeros años del siglo XX, como el objetivo de apropiación de Estados Unidos y otras potencias (UNAM, p.1).

El petróleo, más que ser considerado en el poema como un bien que genere riquezas, como la agricultura, es mostrado como un mal nacional, gracias a la relación que se le da con el diablo. Asimismo, el antagonismo entre el bien y el mal, el vicio y la virtud, aunque esto último no explicitado como bueno o malo necesariamente, pero sí presentado como rasgos opuestos, se evidencia en la siguiente estrofa:

Sobre tu Capital, cada hora vuela

ojerosa y pintada, en carretela;

y en tu provincia, del reloj en vela

28 que rondan los palomos colipavos, las campanadas caen como centavos. 
La carretela de la capital alude, tal como lo sugirió José Emilio Pacheco, a aquellas carretelas de bandera azul que transitaban por la Avenida Madero de principios del siglo XX, cuando servían de transporte a las cortesanas (Pacheco, 1999, p. 356). La mención de las prostitutas en un entorno citadino hace que la ciudad sea exhibida en La suave Patria como aquella vida que invita a la inmoralidad. Una ciudad posrevolucionaria que se alejaba de lo conocido y creaba entre sus habitantes nostalgia por el pasado porfiriano. A decir de Mauricio Tenorio: "la ciudad era como una elegante y malvada mujer fatal despertando de una larga parranda de revoluciones y abusos, descubriéndose resacosa y desarreglada: todo por rehacer" (2017, p. 150).

La provincia, por su parte, ostenta la calma de las campanadas de la Iglesia y la virtud del catolicismo. Martha Canfield (2010) habla del poema como una protesta a favor del campo y en contra la ciudad (párr. 5). De esta forma, el texto, producto centralista, apela al tópico "menosprecio de corte y alabanza de aldea", reconocido éste a partir de la notoria defensa de las virtudes provincianas ante las citadinas, entendidas estas últimas como las de la inminente industrialización posrevolucionaria.

El texto "Menosprecio de corte..." de Antonio de Guevara (1539) señala las bondades de vivir en la aldea y habla de los vicios encontrados en la vida de la corte. La obra está inmersa en un contexto conflictivo planteado por el imperialismo de Carlos $V$ y las prácticas franciscanas. No obstante, una idea utópica dirigía los proyectos políticos y sociales de ambos: el retorno a la Edad de Oro (Rabel, 1992, p. 1). La bonanza, fruto de la vuelta a la época dorada, se encontraba fuera de la corte: "es privilegio de la aldea que allí sean los hombres más virtuosos y menos viciosos, lo cual no es así de cierto en la corte y en las grandes repúblicas, a do ay mil que os estorben el bien y cien mil que os inciten al mal" (De Guevara, 2006, p.30)

La patria provinciana presentada en La suave Patria es esa estabilidad que prometería la Edad de Oro de no haber sido interrumpida por la Revolución. La prosperidad de la nación va de la mano con la religión, el catolicismo que unifica. Y esta fe católica y el amor al terruño acepta resignación, tal como lo sugieren los siguientes versos:

Patria: tu mutilado territorio 
31 se viste de percal y de abalorio.

La relación existente entre la tela y las cuentas de poco valor y la provincia llevó a Juan José Arreola a proponer una vuelta a la "pobreza original" que representaba un ejercicio de superación, pero no como un padecimiento, sino como una acción satisfactoria:

[...] surge inmediatamente la imagen de un pueblo capaz de vivir y revivir más allá de la injusticia. La voluntad de vivir en alegría, envolviendo y adornando las pobrezas en percales y abalorios [...] significa una superación risueña, casi se diría gozosa: tales galas pertenecen a una tradición, y la tradición suntuosa que culmina en el siglo dieciocho, se vuelven aquí ornamentación popular (Arreola, 1997, p. 95).

El juego de simulación que propone Arreola a partir de la idea de una ornamentación de "fantasía" hecha al territorio mexicano propone, asimismo, la defensa de la tradición que no acepta ruptura. Una idea similar es planteada por Canfield (2010), cuando señala que la isotopía entre percalabalorio y patria llevan a sugerir una única posibilidad: "El país destruido se salva volviendo a ser campesino" (párr. 35). Si bien puede tratarse de un par de versos donde los juicios no son favorables a la imagen dada a la patria, al optar por la defensa de una vuelta al pasado rural, sugerida por los estudiosos del texto, existe también la posibilidad de retomar lo propuesto por Bartra, cuando señala la inmovilización ante la industrialización surgida de la Revolución. Creer que asegurar la recuperación económica en el sector campesino impide vislumbrar otras posibilidades que podrían sumarse a la rural.

La exposición de las carencias de la patria continúa en la siguiente estrofa:

Suave Patria: tu casa todavía

es tan grande, que el tren va por la vía

34 como aguinaldo de juguetería.

La idea de La suave Patria como un texto hecho únicamente para conmover e incitar al enamoramiento patrio ha llevado a que la mayoría de sus estudiosos no hagan hincapié en eso que 
reconocen como irónico. El poema, como asegura Víctor Manuel Mendiola (2013): “despertó una emoción compleja y contradictoria", no obstante, las ideas de un texto que:

[...] avanzaba a través de zonas difíciles de entender, pasajes muy barrocos y expresiones inusitadas [...] pasaban casi inadvertidas en el aire de una visión fina, generosa y ligera, bajo la forma de quien da un consejo grato, con una ingravidez de fe, felicidad y humor (párr. 6).

El principio de los opuestos tendría cabida aquí cuando se reconoce que un texto situado en un momento conflictivo puede evidenciar paradojas. Si bien La suave Patria exalta características que elevan el sentido nacionalista, también es posible encontrar expuestos los defectos de la nación, hecho que no implica la decisión de amar u odiar lo evocado, sino a tener una perspectiva completa del conjunto.

El trístico anterior relativo al ferrocarril, llevó a Canfield a afirmar que, gracias a una mirada abarcadora en el texto, la tierra aparece pequeña y manipulable: “Grandes tierras despobladas donde el tren puede ser un acontecimiento: todo se reduce a la dimensión de un juguete" (párr. 12). Más que aceptar esa imagen como una revelación entrañable, resultaría pertinente cuestionar la minimización hecha a un transporte a gran escala como es el tren. Se observa una crítica al monumentalismo romántico (Prado) y al conflicto que representa la noción de la gran patria de la Revolución Mexicana y la suave, pequeña, manejable e infantil como el juguete.

La estrategia poética en La suave Patria puede calificarse como aquella que juega entre un ir y venir que contempla tanto rasgos que elevan el amor patrio como aquellos que derivan en cuestionamientos acerca de la situación social del país. Ambas perspectivas no dejan de ser la realidad nacional del momento posrevolucionario, descrito desde sus diferentes ángulos, los cuales nutren el mosaico conflictivo de la nación. Es así como, después de la minimización hecha a lo que debería ser la gran patria esperada por la Revolución se procede a mostrar aquello que vuelve invaluable a la nación, esto es, las bondades de la madre patria:

35 Y en el barullo de las estaciones, con tu mirada de mestiza, pones 
la inmensidad sobre los corazones.

\section{[...]}

Suave Patria: en tu tórrido festín

luces policromías de delfín,

y con tu pelo rubio se desposa

45 el alma, equilibrista chuparrosa,

y a tus dos trenzas de tabaco sabe

ofrendar aguamiel toda mi briosa

raza de bailadores de jarabe.

Tu barro suena a plata, y en tu puño

50 Su sonora miseria es alcancía;

y por las madrugadas del terruño,

en calles como espejos, se vacía

el santo olor de la panadería.

Cuando nacemos, nos regalas notas,

55 después, un paraíso de compotas,

y luego te regalas toda entera,

suave Patria, alacena y pajarera.

Al triste y al feliz dices que sí,

que en tu lengua prueben de ti

60 la picadura del ajonjolí.

¡Y tu cielo nupcial, que cuando truena

de deleites frenéticos nos llena!

Trueno de nuestras nubes, que nos baña

de locura, enloquece a la montaña, 
requiebra a la mujer, sana al lunático, incorpora a los muertos, pide el Viático, y al fin derrumba las madererías de Dios, sobre las tierras labrantías. Trueno del temporal: oigo en tus quejas crujir los esqueletos en parejas, oigo lo que se fue, lo que aún no toco y la hora actual con su vientre de coco, y oigo en el brinco de tu ida y venida, oh trueno, la ruleta de mi vida.

La voz poética no se vale de la figura masculina de la Revolución para describir al país. En el texto se evidencia el rechazo por la mitología protagonizada, siguiendo a García Morales, por "el macho causante de la discordia y la violencia" (García, párr. 12). La voz lírica opta por afirmar una patria que se adapta satisfactoriamente al estereotipo de lo femenino. Inmersa en sus múltiples oposiciones: La suave Patria manifiesta el antagonismo entre las dos Marías que aluden al modelo, uno positivo y el otro negativo, de la mujer mexicana.

La alusión a la Malinche en el intermedio del poema como aquello parte de lo "sufrido" por Cuauhtémoc evoca el mito que la convirtió en: "la Gran Prostituta pagana: fue la barragana de Hernán Cortés y se ha convertido en el símbolo de la traición femenina" (Bartra, 2017, p. 202). La mujer que la nación mexicana necesita para conservar su virtud no es esa María, sino aquella mujermadre protectora que aparece en el poema capaz de ofrecer cobijo a sus hijos; una madre que con sus paisajes policromos y sus dádivas cotidianas mantenga llenos los corazones del pueblo, se recurre, así, a la alusión que confirma la imagen de la Virgen de Guadalupe como el símbolo protector por excelencia.

La mujer, alegoría de la virtud, es descrita de forma que, sin lugar a dudas, responda al estereotipo ideal femenino, pues será de éste de donde brotarán las cualidades de la Patria. se trata de la mujer casi etérea, inocente, decente y pulcra: 
95 Suave Patria: tú vales por el río de las virtudes de tu mujerío; tus hijas atraviesan como hadas, o destilando un invisible alcohol, vestidas con las redes de tu sol,

100 cruzan como botellas alambradas.

Suave Patria: te amo no cual mito, sino por tu verdad de pan bendito, como a niña que asoma por la reja con la blusa corrida hasta la oreja

105 y la falda bajada hasta el huesito.

Inaccesible al deshonor, floreces; creeré en ti, mientras una mejicana en su tápalo lleve los dobleces de la tienda, a las seis de la mañana,

110 y al estrenar su lujo, quede lleno el país, del aroma del estreno.

El amparo y las virtudes de la patria-madre-mujer no garantizan la estabilidad esperada, por el contrario, el texto muestra la incertidumbre sufrida ante los cambios drásticos producto de la Revolución y el arribo de la modernidad. La pérdida del pasado, un futuro incierto y un presente vacío son las certezas que un contexto en transición puede garantizar. La idea se afirma cuando se lee: "oigo lo que se fue, lo que aún no toco/ y la hora actual con su vientre de coco, / y oigo en el brinco de tu ida y venida, / oh trueno, la ruleta de mi vida". Así como en la siguiente estrofa:

Como la sota moza, Patria mía, en piso de metal, vives al día,

114 de milagro, como la lotería. 
El azar es un síntoma recurrente que no deja pasar desapercibido el juicio que evidencia en los versos la inestabilidad económica del país. De acuerdo con García Morales (2011), en el poema existe una oposición entre la riqueza minera de México y lo azarosa, que, por el contrario, resulta la economía del país (García, párr. 32). Los juegos de azar aparecen como una cualidad pintoresca atribuidas al mexicano que vive confiado en "albures, rifas y loterías, en el mañana Dios dirá" (Del Hoyo, citado por García, 2011, párr. 32) que no proporciona certezas, pero llena de esperanza.

La vida económica y política pareciera suceder bajo los designios del azar, cuando los controles de ciertas decisiones competentes al tema deberían surgir de un poder Ejecutivo certero, no obstante, como si de un juego infantil se tratara, la infraestructura del Palacio Nacional se representa a partir de una minimización:

\section{Tu imagen, el Palacio Nacional, con tu misma grandeza y con tu igual estatura de niño y de dedal.}

El investigador Eugenio del Hoyo hace referencia a la construcción incompleta del edificio en cuestión en el año de 1921, asegura que para una extensión de terreno amplia como en la que estaba asentado contar con dos pisos únicamente resultaba desproporcionado, observación que en el poema no pasa desapercibida (Del Hoyo, citado por García, 2011, párr. 33). No obstante, asegura el analista, lo que puede tomarse como un ejercicio de rima banal ("Nacional", "igual" y "dedal") despierta el interés por la paradoja presentada.

La contradicción sucede de manera similar que con el trístico que involucra las dimensiones del ferrocarril. En este terceto, nuevamente, la imagen de un edificio cuya simbología repercute en el concepto que se pueda tener de la estabilidad nacional en un contexto conflictivo como el evocado es minimizado y comparado con la altura de un niño, lo que implica lo opuesto al ímpetu revolucionario. 
El paisaje cobra importancia en el poema, ya que es a partir de su representación que se pondrá en evidencia aquello que contrasta con lo suave que puede ofrecer la patria. Esta conjetura lleva a cuestionar el punto de vista de Ignacio Sánchez quien señala que La suave Patria es: "el punto final a una larga genealogía de poesía nacionalista del paisaje $y$, sobretodo, la evidencia del agotamiento de esa genealogía" (Sánchez, 2006, p.). Lo anterior, debido a que asegura que en el texto se critica el monumentalismo paisajista empleado en el siglo anterior en poemas de exaltación nacional propios del romanticismo. Por lo que no apela a la crítica a través del paisaje. Agrega, además, que La suave Patria no forma parte de la literatura que contribuye a la constitución de la nación.

El poema, más que un punto final, puede considerarse un punto y seguido, ya que innovó su estética, pero siguió manteniendo la misma funcionalidad de la poesía cívica precedente. Si bien se evitan las exposiciones grandilocuentes del paisaje, no deja de recurrir a las ideas fundamentales de raigambre nacionalista, cuya inserción en el texto pueden atribuirse a un ejercicio de propagación de un sentimiento de pertenencia homogeneizante, lo que lo convierte en una obra que colabora en el fortalecimiento de amor patrio; es decir, que el poema se vuelve directriz en la concepción amorosa que el Estado busca sembrar entre la población hacia el país durante el periodo posrevolucionario.

El parentesco que se puede encontrar con la propuesta estilística del poema y el romanticismo, el cual no permite la total lejanía propuesta por Sánchez, se encuentra en que el romanticismo, como señala Roger Bartra (2017), tendió a descubrir en el idealismo mágico un remedio ante la tragedia del hombre moderno, imbuido en una realidad gris, intransigente y trivial. La fórmula permitía transformar el universo en una agradable metáfora (Bartra, p. 189). De esta forma, La suave Patria no monumentalizó el paisaje como se hiciera en "La grandeza mexicana" (1604) de Balbuena, un poema que pretendió, previo al romanticismo, construir la imagen de la Nueva España ante una mirada extranjera.

\section{La inmovilidad, garantía de felicidad}


En adelante, hasta la culminación del poema, la voz lírica de La suave Patria se valdrá de los rasgos distintivos de la mexicanidad católica para recordar que éstos pueden mantener viva la creencia de un país próspero y feliz:

Te dará, frente al hambre y al obús, un higo San Felipe de Jesús.

La leyenda evocada en este dístico asegura que Felipe de Jesús fue un hombre de excesos, por lo que la madre se preguntaba que cuándo éstos terminarían y él iría por el camino correcto, a lo cual, incrédula, otra mujer aseguró que cuando determinada higuera seca diera frutos. El hombre, al sentir el llamado divino, se retiró a predicar y murió como un mártir; muerte tras la cual la planta retoñó (Canfield, párr. 74). La semejanza hecha entre esta historia y el momento social por el que el país atravesaba permite hacer notar, como Carmen de la Fuente señala, que, ante las dificultades económicas y lo atroz de la guerra, la nación podrá resurgir pues: "el pueblo tendrá siempre como baluartes el candor y la fe emanados de sus leyendas" (párr. 74). Irónico o no, estos dos versos aparecen como el preámbulo esperanzador que sostiene las siguientes estrofas en las que, de nueva cuenta, la voz lírica alude a las bondades de la patria con un tono festivo:

120 Suave Patria, vendedora de chía:

quiero raptarte en la cuaresma opaca,

sobre un garañón, y con matraca,

y entre los tiros de la policía.

La violencia expuesta en estos versos que involucran armas y un rapto resulta inusitada, debido a la ausencia de escenas como ésta durante el poema, no obstante, se suma al panorama un rasgo más de la mexicanidad. La vendedora de chía es el primero de ellos, presente como elemento indispensable en las crónicas costumbristas del XIX (como ejemplo: “Un puesto de chía en Semana Santa" de Guillermo Prieto). 
La importancia de la cuaresma también es recordada y utilizada como fondo para llevar a cabo una práctica social entendida como "el robo de la novia", considerada aún en el siglo XX una práctica rural tradicional (por ejemplo, en Juchitán, Oaxaca o Torreón, Coahuila). Los métodos pueden ser distintos, pues el semental como transporte se sustituye por otros medios menos acordes al del macho revolucionario, quien, como jinete rebelde, raptaba a las mujeres de los ranchos con o sin consentimiento de ellas (Corona, 2013, párr.9).

La virtud de la patria-madre-mujer se fortalece para afirmar el carácter protector de la misma en los siguientes versos:

Tus entrañas no niegan un asilo

125 para el ave que el párvulo sepulta

en una caja de carretes de hilo,

y nuestra juventud, llorando, oculta

dentro de ti el cadáver hecho poma

de aves que hablan nuestro mismo idioma.

130 Si me ahogo en tus julios, a mí baja

desde el vergel de tu peinado denso

frescura de rebozo y de tinaja,

y si tirito, dejas que me arrope

en tu respiración de incienso

135

y en tus carnosos labios de rompope.

Las tradiciones nacionales y el amor al terruño se afianzan en una promesa de consuelo en los momentos de vulnerabilidad. Acción suficiente para proponer la defensa de lo que se tiene tal y como se presenta, con los aciertos y desaciertos inherentes a toda condición social. La inmutabilidad sostenida por el costumbrismo y el catolicismo provinciano propone la necesidad de conservar intacta la naturaleza de las cosas, la cual evade la llegada de la modernidad y la posible influencia religiosa de otras latitudes para salvar el ánima y el estilo de un pueblo creyente: 
Por tu balcón de palmas bendecidas

el Domingo de Ramos, yo desfilo

lleno de sombra, porque tú trepidas.

Quieren morir tu ánima y tu estilo,

140 cual muriéndose van las cantadoras

que en las ferias, con el bravío pecho

empitonando la camisa, han hecho

la lujuria y el ritmo de las horas.

Patria, te doy de tu dicha la clave:

145 sé siempre igual, fiel a tu espejo diario;

cincuenta veces es igual el Ave

taladrada en el hilo del rosario,

y es más feliz que tú, Patria suave.

Sé igual y fiel; pupilas de abandono;

150

sedienta voz, la trigarante faja

en tus pechugas al vapor; $y$ un trono

a la intemperie, cual una sonaja:

¡la carreta alegórica de paja!

La inmovilidad, tal como señala Fernando Ainsa (1998), garantiza la estadía en el Paraíso y, por ende, en la Edad de Oro. Se trata, a decir del investigador de "un orden que básicamente es el de todos los ciclos de la naturaleza que marcan las estaciones del año y el ritmo de cosechas que se repiten en forma monótona, siguiendo leyes divinas" (p. 87)

El antagonismo entre un aquí, planteado desde un contexto posrevolucionario, y un allá, previo a 1921, es presentado en La suave Patria a partir del presagio de muerte del "ánima" y el "estilo" de la patria. El lugar desde el que se enuncian las virtudes de la patria permite concluir que 
lo que no corresponde a estas cualidades aparecen como lo negativo, debido a que el pasado, contenido en la provincia defendida, se diluye ante un futuro amenazador.

El poema encierra una problematización derivada del conflicto entre la tradición y la modernidad. El discurso de la modernidad acompaña el desarrollo de México desde la época virreinal del siglo XVIII (Pérez-Rayón, s/f, p. 1). Específicamente, a partir de 1900 este tópico se entendía como el progreso en el campo de la salud; la edificación de obra pública útil y de ornamentación; la eficacia militar; el avance en las vías aéreas y terrestres de comunicación; descubrimientos biológicos, físicos, químicos y astronómicos; entre otros, que prometían la inserción en una cultura civilizada (Pérez-Rayón, s/f.).

La suave Patria es un poema nacionalista conservador, cuyo contexto de producción concuerda lo expuesto en el texto. De los elementos de la cultura conservadora de los años veinte, que son reconocibles en el poema resaltan: el catolicismo, la fe en la jerarquía eclesiástica, a la que se confiere la interpretación de lo real y conlleva a reprobar la laicidad y el liberalismo en defensa de la moral; la Virgen de Guadalupe como la cumbre de la religiosidad del pueblo; el distanciamiento espiritual de la capital y sus vicios. (Monsiváis, 2008, p. 38).

El poema manifiesta la consciencia cultural de principios del siglo $\mathrm{XX}$, testigo del proceso de transformación causado por la llegada de la modernidad. En el texto se plantea la preocupación de un cambio de los valores tradicionales, expresados a través del paisaje y las costumbres, puestos en riesgo por un contexto posrevolucionario contradictorio que más que dar una bienvenida estructurada y formal al nuevo Estado se presenta caótico. Por lo que la única ruta segura para avanzar hacia un futuro incierto es la conservación de los valores cultivados desde antaño y afianzados por la fe católica: estandarte homogeneizante de la sociedad mexicana.

La composición teatral del poema (Proemio, Primer acto, Intermedio y Segundo acto) lleva a considerar a La suave Patria como una representación escénica donde la Patria es el personaje principal; instalada en una escenografía que expone el paisaje mexicano, su colorido y sus sabores. Con acotaciones extensas que definen las características afables de una madre patria bondadosa. Una puesta en escena, donde, además, las estrofas pareadas funcionan como el coro griego que 
daba a conocer al público las partes de la historia que no era posible identificar sobre el escenario y que, en el poema, son aquellas partes ásperas que oscurecen el panorama pintoresco que debería ser la nación: una provincia católica alejada del vicio, una niñez virtuosa salvaguardada por lo esencialmente mexicano.

\section{Conclusiones}

La suave Patria de Ramón López Velarde es un texto en el que es posible identificar una crítica al contexto posrevolucionario. El poema evidencia un momento social conflictivo en el que aspectos negativos y positivos configuran a la nación. No obstante, son aquellos elementos de afirmación nacional los que determinan el reconocimiento del texto, ya que forman parte del constructo referente al mito del nacionalismo mexicano, por lo que su peso es mayor a los juicios negativos que evidencian lo contradictorio del ambiente político, económico y social del nuevo Estado mexicano.

El poema, asimismo, es una obra posrevolucionaria, ya que expresa el discurso nacionalista distintivo de ese periodo, aquel que eleva el amor patrio. El espiritualismo filosófico es uno de los principales rasgos que permiten vincularlo a la producción artística del periodo en cuestión. El modernismo filosófico promovido por pensadores como Emmanuel Kant o Arthur Schopenhauer y el extendido por Hispanoamérica por José Enrique Rodó proponían el progreso a partir de la auto comprensión cultural; esto es, el redescubrimiento y aceptación de lo propio. De esta forma, lo "auténticamente mexicano" queda expuesto en La suave Patria y es el pilar que encubre los aspectos conflictivos de la nación.

La suave Patria no debe considerarse como un cándido juego de versificación. Por la sujeción al programa de Estado al que responde sí se puede ver como un texto que se valió de un lenguaje popular para llegar al pueblo, pero que no por ello dejó de lado el uso sagaz de las palabras. El poema presenta una imagen suavizada del país, mas no oculta por completo las dificultades que también le son propias. Por ello, rescata el rostro afable de la sociedad mexicana, para que sea eso, 
la propia identidad, lo que salve a la nación envuelta en un nuevo cambio histórico determinante, al que se enfrentaba esperanzado, pero con miedo e incluso renuente a la inminente transformación.

Las celebraciones por el centenario de La suave Patria están aquí y el poema se renueva por su actualidad. Las circunstancias sociales son adversas, no obstante, hay un intento por parte del Estado de hacer creer que todos los mexicanos son felices, sin considerar la composición heterogénea del país y minimizando las carencias sociales que es necesario combatir. Persiste un gobierno que pretende plantear una postura idealizada de las circunstancias sociales antes que afrontar la realidad tal como se presenta. Asimismo, la promesa de autosuficiencia hace renacer la esperanza del pueblo mexicano a pesar de las adversidades económicas que acechan a la industria petrolera, minera y agrícola. Por su parte, el guadalupanismo, fiel a su imagen, continúa siendo un rasgo identitario de la sociedad mexicana y es el que mantiene la fe de un pueblo que vive en la incertidumbre.

Tal vez, en su aniversario, La suave Patria sea la lectura recomendada por el gobierno como lo fue la Cartilla moral de Alfonso Reyes al inicio del nuevo mandato presidencial. La invitación a leer el texto debe ser aceptada, pero no sólo para llevar a cabo un ejercicio de repetición que fortalezca el amor patrio, como sucedió en el siglo anterior, sino como una acción que derive en una mirada retrospectiva capaz de ver, desde una visión crítica, los aciertos y desaciertos de la nación.

\section{Referencias}

Ainsa, F. (1998). De la Edad de Oro al Dorado. Génesis del discurso utópico americano. https://es.scribd.com/doc/35780972/De-La-Edad-de-Oro-a-El-Dorado

Barthes, R. (1966). Investigaciones retóricas I. La retórica antigua. Buenos Aires. Argentina. Ediciones Buenos Aires. 
Campos, L. (2017). Cuauhtémoc, "el héroe completo". La conmemoración del último emperador azteca en la Ciudad de México durante el porfiriato (1887-1911).

http://www.scielo.org.mx/scielo.php?script=sci arttext\&pid=S244865312017000201819

Canfield, M. L. (2010). La provincia inmutable. Estudios sobre la poesía de Ramón López Velarde. Biblioteca Virtual Miguel de Cervantes. http://www.cervantesvirtual.com/obra-visor/laprovincia-inmutable-estudios-sobre-la-poesia-de-ramon-lopez-velarde/html/c3fef07f-f3794a70-bbda-5c6148d2104d 25.htm|\#l 13

Cros, E. (1986). Literatura, ideología y sociedad. Madrid. España: Gredos.

De Aguinaga, L. V. (2016). De la intimidad. Emociones privadas y experiencias públicas en la poesía mexicana. Ciudad de México. México: Fondo de Cultura Económica.

De Guevara, A. (2006). Menosprecio de corte y alabanza de aldea. Biblioteca Virtual Universal. https://www.biblioteca.org.ar/libros/131878.pdf

Di Giminiani, P. y Fonck, M. (2015) El paisaje como proceso de vida: experiencias de domesticación del bosque en el sur de Chile. Revista de Geografía Norte Grande, núm. 61. Santiago. Chile. https://www.redalyc.org/pdf/300/30041119002.pdf

Foxley, C. (2016). La ironía, funcionamiento de una figura literaria. Revista Chilena de Literatura, (910). https://revistaliteratura.uchile.cl/index.php/RCL/article/view/41758/43253

García, A. (2011). López Velarde 1921: la médula guadalupana de “La Suave Patria”. Biblioteca virtual Miguel de Cervantes. http://www.cervantesvirtual.com/obra-visor/lopez-velarde1921-la-medula-guadalupana-de-la-suave-patria/html/968a0e68-59d7-11e0-b86400163ebf5e63 3.html\#| 0

Genette, G. (2001). Umbrales. Ciudad de México. México.: Siglo XXI Editores.

Grigoriadu, T. (2010). “La obra de Luciano Samosantense, orador y filósofo excelente” Manuscrito 55 de la Biblioteca Menéndez y Pelayo: edición y estudio. (Memoria para optar al grado de Doctora). https://eprints.ucm.es/10598/1/T31864.pdf

Hesiodo. (2016) Los trabajos y los días. https://es.scribd.com/read/319311574/Los-trabajos-y-los$\underline{\text { dias\# }}$ 
Kierkegaard, S. (2000). Escritos de Søren Kierkegaard. Madrid. España: Ediciones Trotta.

Le Corre, H. (2010). Ramón López Velarde: visión y versión de la Patria. Biblioteca Virtual Miguel de Cervantes. http://www.cervantesvirtual.com/nd/ark:/59851/bmckw600

López, R. (1986). Ramón López Velarde. Obras. Ciudad de México. México: Fondo de Cultura Económica.

Maderuelo, J. (2005). El paisaje. Génesis de un concepto.

https://es.scribd.com/document/337928396/El-Paisaje-Genesis-de-Un-ConceptoMaderuelo-pdf

Mendiola, V. M. (2013) Las circunstancias de La suave Patria. Nexos.

\section{http://www.nexos.com.mx/?P=leerarticulo\&Article=2204029}

Milton, J. (2003). El paraíso perdido. Biblioteca Virtual Universal.

https://www.biblioteca.org.ar/libros/656292.pdf

Pacheco, J. E. (1999). Antología del modernismo 1884-1921.

https://es.scribd.com/document/369148996/Jose-Emilio-PachecoAntologia-Del-

\section{$\underline{\text { Modernismo }}$}

Paz, O. (1963). El camino de la pasión. https://www.biblioteca.org.ar/libros/154004.pdf

Tenorio, M. (2017). "Hablo de la ciudad" Los principios del siglo XX desde la Ciudad de México. Ciudad de México. México: Fondo de Cultura Económica.

Rabell, C. (1992) Menosprecio de corte y alabanza de aldea: ¿Crítica lascasiana, propaganda imperialista o "best-seller"? AIH. Actas XI. Centro Virtual Cervantes. https://cvc.cervantes.es/literatura/aih/pdf/11/aih 113 028.pdf 